\title{
O PROCESSO DE RESTAURAÇÃO FLORESTAL ENTRE OS GUARANI-NHANDEWA DA TERRA INDÍGENA LARANJINHA (SANTA AMÉLIA, PR)
}

VITOR RENCK MACIEL ${ }^{1}$

UFSCar

LUIZ ANTONIO NORDER ${ }^{2}$

UFSCAr

\begin{abstract}
RESUMO: A Terra Indígena Laranjinha, habitada pela etnia Guarani-Nhandewa, no norte do Paraná, foi submetida, a partir dos anos 50, a uma intensa destruição de seus recursos naturais para exploração madeireira e abertura de áreas agrícolas e de pastagens. No entanto, a comunidade decidiu, a partir do final da década de 1990, realizar um manejo de determinadas áreas para fins de restauração de florestas nativas. Com um controle rigoroso do fogo, começaram a conduzir a regeneração natural. O presente artigo analisa o histórico ambiental desta terra indígena, desde o desmatamento até o processo recente de restauração florestal, procurando compreender seus principais aspectos ambientais, econômicos e socioculturais. Foram realizadas entrevistas semiestruturadas, bem como incursões às áreas em restauração com a finalidade de identificar suas principais características florísticas. A pesquisa mostra que, em 2012, a cobertura com florestas nesta terra indígena era de, aproximadamente, $35 \%$ do total, em vários estágios sucessionais, sendo que há 20 anos a cobertura florestal foi estimada em 3,6\% do total. A floresta (re)criada permite uma ampliação dos recursos, contribui para redefinição da identidade social e para revalorização de suas tradições.
\end{abstract}

PALAVRAS-CHAVE: Guarani-Nhandewa; restauração florestal; história ambiental.

ABSTRACT: The Laranjinha Indigenous Land, inhabited by the Guarani-Nhandewa indigenous community, is located in northern Paraná, Brazil, and has undergone an intense devastation of its natural resources for the expansion of agricultural areas and pasture for cattle breeding. Although this historical process, the community decided, in the late 1990s, to start a management in specific areas aiming a restoration of native forests. With strict control of fire, the community began to handle some pasture lands to allow natural regeneration. This article examines the environmental history of this indigenous territory, seeking to understand its ecologic, economic, cultural and social aspects. Semi-structured interviews were conducted as well as incursions into the restored areas to identify its main floristic profile,. The research shows that, in 2012, the forest covered approximately 35\% of the area, in vari[[ous ecological stages; it was estimated 20 years ago a coverage of $3.6 \%$. The forest recreated allows an

\footnotetext{
${ }^{1}$ Ecólogo, graduado pela Universidade Estadual Paulista Júlio de Mesquita Filho, UNESP; Mestre em Agroecologia e Desenvolvimento Rural pela Universidade Federal de São Carlos, UFSCar. E-mail: vitor_renck@hotmail.com .

${ }^{2}$ Professor do Programa de Pós-Graduação em Agroecologia e Desenvolvimento Rural da Universidade Federal de São Carlos (PPGADR/UFSCar). E-mail: luiz.norder@cca.ufscar.br .
}

Espaço Ameríndio, Porto Alegre, v. 8, n. 2, p. 108-126, jul./dez. 2014. 
VITOR RENCK MACIEL e LUIZ ANTONIO NORDER- O processo de restauração florestal...

increasing in resources and contributes to the maintenance and redefinition of their cultural identity, values and traditions.

KEYWORDS: Guarani-Nhandewa; forest restoration; environmental history.

Introdução

Pesquisas recentes apontam as reservas indígenas, sobretudo no contexto amazônico, como grandes mantenedoras da biodiversidade (TOLEDO, 2003; NEPSTAD et al., 2006; DIEGUES, 2008). Elas seriam, inclusive, mais eficientes na conservação da natureza em comparação com as Unidades de Conservação de Proteção Integral, ou seja, reservas florestais que restringem amplamente a presença humana em seu interior. Este quadro comparativo favorável às terras indígenas decorre, entre outros fatores, da combinação entre sistema tradicional de manejo dos recursos naturais e a adoção de novas linhas de ação política por parte das comunidades. Além disso, a presença desses povos inibe, através de diversos mecanismos, o estabelecimento de atividades ilegais vinculadas ao desmatamento, às queimadas e à abertura de novas áreas de pastagem.

Este processo vem ocorrendo nas últimas décadas em diferentes regiões do território nacional. Por outro lado, há um conjunto de restrições e impasses na demarcação de terras indígenas. Na porção centro-sul do país, as comunidades indígenas, cuja população é crescente, contam com áreas bastante reduzidas e, em alguns casos, não há quaquer reconhecimento e demarcação de territórios (BERTONCINI e RODRIGUES, 2008). Além disso, conflitos fundiários criam um estado de tensão nestas áreas, já afetada pela violência contra os indígenas, pela alta mortalidade infantil e por uma grave incidência de subnutrição e alcoolismo (ALMEIDA e MURA, 2003).

Esta situação, ao menos em parte, é encontrada também na Terra Indígena (TI) Laranjinha, ou Tekoá Narai, como é conhecida pelos seus habitantes. Inserida em uma região marcada por uma intensa 
VITOR RENCK MACIEL e LUIZ ANTONIO NORDER- O processo de restauração florestal...

devastação de seus recursos naturais a partir de meados da década de 1930, quando as primeiras serrarias chegaram à região (MATOS e BARROS, 2006), a terra indígena chegou, na década de 1950, a ter o seu desmatamento oficialmente incentivado pela política integracionista promovida pelo Serviço de Proteção aos Índios (SPI), antigo órgão do Governo Federal encarregado de executar a política indigenista. Entre seus objetivos estava a pacificação e a integração dos índios à sociedade brasileira e o seu engajamento no processo produtivo (BORGES e BORGES, 2009).

Pertencentes à etnia Guarani-Nhandewa, os indígenas da Terra Indígena Laranjinha tradicionalmente recorrem às florestas para realizar parte das atividades cotidianas que configuram o seu modo de vida: madeira e fibras são utilizadas na confecção de artesanato e em construções; frutos e tubérculos são coletados para compor sua alimentação; folhas e madeira são usadas para fins medicinais e ritualísticos. Porém, dado o intenso processo de desmatamento, esta relação com a floresta foi em grande medida interrompida.

A vida guarani está fortemente ligada à agricultura e à floresta - e a ocupação de determinados territórios reflete sua cultura, ao mesmo tempo em que também a constitui (BARROS, 2003). Para os Guarani, o território habitado, chamado tekohá, tem uma importância fundamental no seu modo de organização. Segundo Almeida e Mura (2003), o tekohá representa o espaço físico onde se realiza a vida guarani, o teko (modo de ser guarani). É nesse espaço que se dão as relações familiares, as atividades religiosas, econômicas e outras que compõem a vida cotidiana. O tekohá deve ser um lugar que reúna condições físicas (geográficas e ambientais) e estratégicas adequadas à vida de todo o grupo (NIMUENDAJU, 1987).

Os Guarani da Terra Indígena Laranjinha, antes detentores de um vasto território pelo qual se deslocavam constantemente (CAVALIN e NOGUEIRA, 2009), atualmente ocupam um território, demarcado em 1988, que soma 291 hectares, bastante reduzido para um total de 46 famílias. Por esse motivo, os Guarani da TI Laranjinha vêm lutando, desde o início da década de 1990, por uma ampliação de seu território até as margens do Rio Laranjinha, a uma distância de sete quilômetros (em linha reta). Após deliberação da Fundação Nacional do Índio 
VITOR RENCK MACIEL e LUIZ ANTONIO NORDER- O processo de restauração florestal...

(FUNAl), foi designado em 2003 um Grupo de Trabalho (GT) multidisciplinar, liderado pela antropóloga Juracilda Veiga, com a finalidade de dar continuidade aos estudos feitos para identificação e delimitação da atual área da TI. O GT propôs a criação de outra TI à beira do Rio Laranjinha, com 1.238 hectares de extensão territorial (ou seja, mais de quatro vezes o tamanho da TI Laranjinha). A nova TI, denominada de Yvyporã Laranjinha, foi declarada pelo Ministério da Justiça em 2007.

Neste contexto, o objetivo deste artigo é analisar o histórico ambiental da TI Laranjinha, desde seu processo de desmatamento, particularmente intenso a partir da década de 1950, até o recente manejo e restauração florestal promovido pela comunidade. Tendo em vista a ausência de registros documentais mais detalhados sobre este processo, a pesquisa foi realizada com base em métodos qualitativos e etnográficos. Em seguida, foi realizada uma identificação do estágio de sucessão das áreas em processo de restauração e um mapeamento do uso do solo, que inclui um dimensionamento da atual cobertura florestal na Terra Indígena. Um futuro levantamento florístico mais detalhado na área estudada poderá complementar as análises aqui apresentadas.

\section{Metodologia da pesquisa}

A pesquisa de campo, realizada entre julho de 2011 e setembro de 2012, incluiu observações e entrevistas utilizando questionário semiestruturado sobre o tema da pesquisa (BERNARD, 1998; VIERTLER, 2002). Entre os entrevistados, estavam, principalmente, pessoas com 50 anos ou mais, que relataram o histórico de desmatamento e reflorestamento na área e na região. Foram realizadas 10 entrevistas qualitativas semiestruturadas junto a um grupo heterogêneo, abrangendo homens e mulheres, funcionários da Funai e algumas lideranças comunitárias, sobretudo o cacique. As entrevistas permitiram o levantamento de informações sobre a percepção dos entrevistados sobre o histórico florestal da aldeia, desde o processo de desmatamento até a conversão, mais recentemente, de áreas de pastagem em floresta, 
VITOR RENCK MACIEL e LUIZ ANTONIO NORDER- O processo de restauração florestal...

com ênfase para a forma como manejaram essas áreas e os novos usos da floresta em restauração, entre outras questões afins.

Para a realização do mapeamento e dimensionamento do uso do solo e da cobertura florestal, foram realizadas incursões por toda a terra indígena e efetuada uma coleta de informações florísticas em diversos pontos de cada fragmento florestal (ou em processo de restauração florestal) com a finalidade de identificar seus respectivos estágios sucessionais e espécies-chave. Para tanto, foram utilizados os parâmetros para a classificação de estágios de sucessão da Mata Atlântica estabelecidos pela Resolução CONAMA $n^{\circ} 10$, de 01 de outubro de 1993.

A elaboração de mapa de uso do solo e da cobertura florestal foi realizada através de imagem de satélite da área de estudo (datada em 18 de setembro de 2010 e disponibilizada pelo sistema Google Earth) processada no software ArcGIS 9. Foram definidas e dimensionadas sete classes de uso do solo: hidrografia, agropecuária, ocupação habitacional, área de futura restauração, floresta em estágio inicial, floresta em estágio médio e floresta madura.

Este trabalho foi autorizado pelas lideranças da comunidade e pela FUNAI (Fundação Nacional do Índio) e aprovado pelo Comitê de Ética em Pesquisa em Seres Humanos da Universidade Federal de São Carlos.

\section{Caracterização da área de estudo}

O presente trabalho foi realizado na TI Laranjinha, localizada no município de Santa Amélia, norte do estado do Paraná (23 $17^{\prime} 03.96 " \mathrm{~S}$ e $50^{\circ} 24^{\prime} 33.33^{\prime \prime}$ )). A região está situada na Bacia Hidrográfica do Rio Laranjinha, afluente do Rio Paranapanema, que divide os estados de São Paulo e Paraná (VIEIRA, 2004). Sua precipitação média anual oscila entre 1400 e $1600 \mathrm{~mm}$. Apresenta clima do tipo Cfa, subtropical úmido com verão quente, geadas pouco frequentes e tendência de concentração das chuvas nos meses de verão, sem estação seca definida (KÖEPPEN, 1948). A temperatura média anual é de 21 graus Celcius $\left({ }^{\circ} \mathrm{C}\right)$, ficando a média 
VITOR RENCK MACIEL e LUIZ ANTONIO NORDER- O processo de restauração florestal...

do mês mais quente em $28{ }^{\circ} \mathrm{C}$ e do mês mais frio em $16{ }^{\circ} \mathrm{C}$ (CAVIGLIONE et al., 2000).

Pertencente ao domínio da Mata Atlântica, sua tipologia vegetacional dominante é a Floresta Estacional Semidecidual, caracterizada pela dupla estacionalidade climática: uma tropical com época de intensas chuvas de verão, seguida por estiagem acentuada, e outra subtropical sem período seco, com seca fisiológica provocada pelo intenso frio do inverno. Neste tipo de fitofisionomia, a porcentagem das árvores caducifólias situa-se entre 20 e 50\% (INSTITUTO BRASILEIRO DE GEOGRAFIA E ESTATÍSTICA, 1992; VELOSO, RANGEL FILHO e LIMA, 1991; RODERJAN et. al., 2002).

Com altitude variando de 420 metros, no limite oeste junto ao Ribeirão da Onça, a 580 metros, em seu limite norte, possui declividade pouco acentuada, predominando aquelas inferiores a $12^{\circ}$. As formas de relevo na $\mathrm{TI}$ e região de entorno apresentam topos arredondados a localmente achatados, vertentes com perfis convexos a eventualmente retilíneos. O Ribeirão da Onça é o principal curso d'água na terra indígena, para o qual deságua o Ribeirão Grande (VIEIRA, 2004).

A população da Terra Indígena Laranjinha oscila em função das práticas migratórias que caracterizam a cultura guarani. Há um constante deslocamento a outras terras indígenas da região, como São Jerônimo, Pinhalzinho e Araribá. Em 2012, a aldeia vinha sendo habitada por 46 famílias, num total de 280 pessoas da etnia Guarani-Nhandewa, distribuídas em 291 hectares.

A comunidade tem seus meios de vida basicamente associados à agricultura e ao trabalho assalariado temporário na região, sobretudo no plantio e corte de cana-de-açúcar, ou ainda em contratações ocasionais para a realização de serviços gerais em fazendas da região (BARROS, 2003). Também é de grande relevância na comunidade o acesso à previdência social (VEIGA, 2004).

A TI Laranjinha está inserida numa região de agricultura mecanizada voltada para a produção de soja, milho, algodão, café e cana-de-açúcar, com algumas áreas de pastagens (VIEIRA, 2004). Aos poucos, essas culturas vêm sendo substituídas pela soja (em geral, transgênica). Nos últimos anos, 53 hectares desta TI vinham sendo destinados à agricultura de cultivos comerciais de grande escala, em

Espaço Ameríndio, Porto Alegre, v. 8, n. 2, p. 108-126, jul./dez. 2014. 
VITOR RENCK MACIEL e LUIZ ANTONIO NORDER- O processo de restauração florestal...

sistema de monocultura e com o emprego de implementos agrícolas e práticas da agricultura convencional, como a aplicação de fertilizantes sintéticos e o controle químico de pragas e ervas adventícias. Nessa área, as principais culturas foram: trigo, alfafa, algodão e, principalmente, a soja. Assim como na região, a soja cultivada na TI Laranjinha era transgênica.

Em áreas menores, mais próximas às residências, cada família mantém pequenos roçados, onde há o cultivo de milho, mandioca, feijão, batata doce, arroz, entre outros gêneros alimentícios, sobretudo para o autoconsumo. Algumas famílias possuem pomar, uma pequena horta e a criação de porcos e galinhas. Ainda assim, boa parte da alimentação tem sido oriunda de produtos adquiridos no mercado local e regional.

\section{O histórico de devastação}

O processo de desmatamento ocorrido na TI Laranjinha foi simultâneo e semelhante ao do norte do Paraná. A partir da década de 1920, com a concessão de terras para empresas de colonização privadas (como a gigantesca Companhia de Terras Norte do Paraná CTNP) pelo Governo do Paraná, atrelada à abertura e expansão de uma rede rodoviária e ferroviária, e com a chegada das primeiras serrarias à região, houve intensa extração de madeira para sua exploração econômica. A madeira mais visada naquele período era a peroba-rosa (Aspidosperma polyneuron Muell. Arg.), dada sua abundância e excelente qualidade para a construção civil. Após um período de extração intensiva de madeiras, as áreas eram destinadas, sobretudo, à produção agropecuária (CANCIAN, 1974; MATOS e BARROS, 2006).

Nas décadas de 1980 e 1990, a região apresentava uma paisagem florestal altamente fragmentada, com poucos remanescentes, preservados apenas parcialmente, o que comprometeu a funcionalidade dos processos ecológicos para a manutenção da biodiversidade local. $\mathrm{Na}$ Terra Indígena Laranjinha, restou apenas um fragmento, parcialmente preservado, conhecido como Matão do Bertolino, referência a um ancião rezador e liderança na comunidade, que protegia e habitava as 
VITOR RENCK MACIEL e LUIZ ANTONIO NORDER- O processo de restauração florestal...

adjacências daquele remanescente, ou simplesmente Matão, que abrange, aproximadamente, 11 hectares (4\% da área total). Sua peculiaridade é a de ter sido o único fragmento florestal desta terra indígena que não chegou a ser completamente derrubado ao longo do processo de desmatamento.

Trata-se de uma floresta remanescente com sinais de degradação, a exemplo da presença de muitas clareiras tomadas por cipós e da densidade elevada de espécies heliófitas como o pau-d'alho (Gallesia integrifolia Spreng.). No entanto, há a ocorrência de espécies típicas de estágios sucessionais avançados, como a baga-de-morcego (Trichilia casaretti C.DC) e o pau-rainha (Actinostemon concolor Spreng.), bem como espécies endêmicas da região, como Exostyles godoyensis Soares-Silva e Mansano, da família botânica Fabaceae, encontrada até o momento em apenas dois outros fragmentos florestais da região, conforme entrevista realizada em março de 2012 com José Marcelo Torezan e Alba Lúcia Cavalheiro, do Laboratório de Biodiversidade e Restauração de Ecossistemas da Universidade Estadual de Londrina (Labre/UEL).

\section{O processo de restauração florestal}

A partir desse histórico de perturbações ambientais, a comunidade decidiu, na segunda metade da década de 1990, iniciar um manejo em algumas áreas da aldeia visando a restauração florestal. Com a deliberação de regras internas restringindo o uso do fogo que resultasse em incêndios não intencionais, e sem o plantio de mudas, começaram a manejar algumas áreas de pastagem e a conduzir a regeneração natural.

A princípio, de acordo com diversos relatos de indígenas e funcionários da Funai, criou-se nessas áreas uma forma de manejo que pode ser caracterizada como um sistema silvipastoril, uma vez que foi sendo consorciado o gado com as espécies vegetais arbóreas nativas regenerantes. Com o crescimento das regenerantes e a formação de um bosque sombreado, a intensidade do rebanho bovino foi sendo 
VITOR RENCK MACIEL e LUIZ ANTONIO NORDER- O processo de restauração florestal...

gradualmente reduzida até a sua completa retirada, o que permitiu a continuidade da sucessão ecológica.

A regeneração natural na Terra Indígena Laranjinha provém, nomeadamente, de propágulos oriundos de outros fragmentos florestais, dentro ou fora da aldeia. Há a dispersão, principalmente, por aves, morcegos e mamíferos. Morcegos frugívoros, particularmente, exercem um papel muito importante nos primeiros estágios da sucessão ecológica, pois, diferentemente das aves, apresentam o comportamento de defecar durante o vôo, dispersando uma grande quantidade e variedade de sementes em áreas abertas (THOMAS et al., 1988). Além disso, percorrem grandes distâncias, visitando diferentes habitats em uma única noite (BERNARD e FENTON, 2003).

A pecuária também teve um papel fundamental no processo sucessional. Em baixas densidades, 0 gado se alimenta, predominantemente, das gramíneas invasoras, o que auxilia o estabelecimento de espécies nativas e reduz o risco de queimada da pastagem. Além disso, é possível que o gado tenha atuado como agente dispersor de algumas espécies palatáveis (NOGUEIRA e NOGUEIRA, 1991).

O banco de sementes teve atuação pouco significante na sucessão secundária, pois poucas espécies possuem sementes com capacidade para continuarem viáveis após sucessivas queimadas, manejo anteriormente utilizado nestes talhões dedicados à pecuária bovina. A perturbação contínua de uma área pode levar ao esgotamento progressivo do banco de sementes, tornando o local com restrições para regenerar a primeira fase da sucessão (KAGEYAMA, CASTRO e CARPANEZZI, 1989).

Após um período de aproximadamente quinze anos, as áreas assim manejadas demonstraram ter uma boa resiliência, apresentando grande potencial de autorrecuperação local. Atualmente, o que se observa nessas áreas anteriormente desmatadas é uma floresta fisionomicamente densa, com boa diversidade de espécies, com vegetação de gramínea praticamente ausente. Percebe-se a predominância de algumas espécies vegetais, como o mutambo (Guazuma ulmifolia Lam.), a gurucaia (Parapiptadenia rigida Benth.), a sapuva (Machaerium stipitatum DC.), a guabiroba-amarela 
VITOR RENCK MACIEL e LUIZ ANTONIO NORDER- O processo de restauração florestal...

(Campomanesia sp.), a Dalbergia frutescens Vell., a lixeira (Curatella americana L.) e o açoita-cavalo (Luehea divaricata Mart.). Essas espécies-chave propiciam condições para o estabelecimento de outras, pois muitas espécies animais (potenciais dispersoras) somente frequentam esses ambientes depois de formado, ainda que minimamente, um bosque.

Diversos fatores motivaram a comunidade a realizar esta restauração florestal que iria substituir boa parte de suas áreas até então destinadas à pecuária e, em menor escala, à agricultura. Há, na própria comunidade, diversos fatores explicativos recorrentes para este processo de restauração florestal. Os Guarani da Terra Indígena Laranjinha percebem a restauração florestal como uma estratégia de revalorização e de resgate cultural, dada a importância do extrativismo como fonte de alimentação e para a obtenção de plantas medicinais, lenhas, fibras, materiais de construção etc. Foi realizado um levantamento do uso potencial de produtos florestais, conforme indicação pela comunidade, como mostra o Quadro 1 .

Quadro 1 - Potencial de uso de produtos florestais na Terra Indígena Guarani Laranjinha, Santa Amélia/PR (2012).

\begin{tabular}{|l|l|l|}
\hline Nome Popular & Nome Científico & Principais usos indicados \\
\hline Açoita-cavalo & Luehea divaricata & $\begin{array}{l}\text { Construção, medicinal, } \\
\text { outros }\end{array}$ \\
\hline Amora branca & Maclura tinctoria & Alimentação \\
\hline Araribá & Centrolobium tomentosum & Alimentação, construção \\
\hline Assa-peixe & Vernonia polysphaera & Medicinal, outros \\
\hline Bambu & n.d. & Artesanato, rituais \\
\hline Canela & Ocotea sp. & Alimentação, construção \\
\hline Caixeta & Tabebuia cassinoides & Construção, outros \\
\hline Cedro & Cedrela fissilis & $\begin{array}{l}\text { Artesanato, construção, } \\
\text { rituais }\end{array}$ \\
\hline Cipó Imbé & Philodendron bipinnatifldurn & Artesanato \\
\hline Conta & Coix lacryma-jobi & Artesanato \\
\hline Copaíba & Copaifera langsdorfii & Medicinal \\
\hline Erva de Santa Maria & Chenopodium ambrosioides & Medicinal \\
\hline Espinheira santa & Maytenus ilicifolia & Medicinal \\
\hline Goiaba & Psidium guajava & Alimentação, medicinal \\
\hline Guaçatonga & Casearia sylvestris & Medicinal \\
\hline Guaricana & Geonoma schottiana & Construção \\
\hline Gurucaia & Parapiptadenia rigida & Construção \\
\hline Indaiá & Attalea dubia & Alimentação, Construção \\
\hline
\end{tabular}

Espaço Ameríndio, Porto Alegre, v. 8, n. 2, p. 108-126, jul./dez. 2014. 
VITOR RENCK MACIEL e LUIZ ANTONIO NORDER- O processo de restauração florestal...

\begin{tabular}{|l|l|l|} 
Jangada & Alchornea triplinervia & Artesanato \\
\hline Jaracatiá & Jacaratia spinosa & Alimentação, Construção \\
\hline Jerivá & Syagrus romanzoffiana & Alimentação, Construção \\
\hline Leucena & Leucaena leucocephala & Artesanato, lenha \\
\hline Lixeira & Aloysia virgata & Alimentação, Construção \\
\hline Marfim & Balfourodendron riedelianum & Artesanato \\
\hline Mutambo & Guazuma ulmifolia & Medicinal, outros \\
\hline Nêspera & Eriobotrya japonica & Artesanato \\
\hline Olho de Cabra & Ormosia arborea & Artesanato \\
\hline Palmito juçara & Euterpe edulis & Alimentação \\
\hline Pau d'alho & Gallesia integrifolia & Artesanato \\
\hline Peroba-rosa & Aspidosperma polyneuron & Alimentação, outros \\
\hline Porongo (cabaça) & Lagenaria vulgaris & Construção \\
\hline Pupunha & Bactris gasipaes & Construção, alimentação \\
\hline Santa Bárbara & Melia azedarach & Artesanato, lenha \\
\hline Sapê & Imperata brasiliensis & Alimentação \\
\hline Taquara & n.d. & Artesanato, construção \\
\hline Urucum & Bixa orellana & Construção, medicinal \\
\hline
\end{tabular}

Fonte: Pesquisa de campo, 2011/2012.

Algumas espécies são alóctones, outras, como goiaba, leucena, nêspera e santa bárbara, são exóticas e apresentam potencial para invadir áreas naturais.

Além disso, existe claramente a percepção da necessidade da recuperação florestal, não só pela possibilidade do uso de seus recursos, mas como uma forma de manter ou recolocar o ambiente em equilíbrio.

Quanto ao aspecto financeiro, além de ter sido promovida uma restauração de baixíssimo custo (em razão do manejo adotado), houve um incentivo direto do órgão ambiental estadual, no caso, o Instituto Ambiental do Paraná (IAP), para a restauração florestal da Terra Indígena, tendo em vista o repasse de verbas para a aldeia através do ICMS Ecológico (Imposto sobre Circulação de Mercadorias e Serviços). No Paraná, estado pioneiro na adoção do ICMS Ecológico como política pública, 2,5\% da arrecadação total do ICMS é destinada aos municípios que possuem Unidades de Conservação ou outras áreas protegidas, entre as quais, as Terras Indígenas. O cálculo do benefício que o município recebe tem como base a sua área florestal e seu estado de conservação, avaliados por técnicos do IAP (MATTOS e HERCOWITZ, 2011).

Espaço Ameríndio, Porto Alegre, v. 8, n. 2, p. 108-126, jul./dez. 2014. 
O valor recebido pelo município de Santa Amélia varia anualmente em função da arrecadação do ICMS no Estado. Parte desse montante é destinada à Terra Indígena Laranjinha; em 2011, o repasse foi de, aproximadamente, $\mathrm{R} \$ 5.000,00$ mensais, valor utilizado, por exemplo, no preparo do solo e em outras atividades agrícolas. Segundo um antigo cacique, "a terra é arada e preparada com trator e depois dividida entre as famílias para cultivarem" (VEIGA, 2004, p. 50).

Outros dois fatores foram relevantes para a tomada de decisão. $O$ elemento topográfico é um deles. A maior parte das áreas selecionadas para fins de restauração possuía uma declividade relativamente acentuada, podendo chegar a $20^{\circ}$ (VIEIRA, 2004), o que limita o uso para a agricultura mecanizada, pelo menos da forma como vinha sendo realizado em outros talhões. Além disso, os Guarani não tinham uma tradição de lidar com a pecuária bovina, o que dificultou a continuidade desta atividade nas áreas em processo de restauração florestal. De qualquer forma, a comunidade não destinou estas áreas, por exemplo, à produção de eucalipto, como muito frequentemente ocorre em áreas similares em propriedades particulares na mesma região.

\section{Caracterização da cobertura florestal atual}

A cobertura florestal na Terra Indígena Laranjinha na década de 1980, de acordo com as informações obtidas na pesquisa de campo, correspondia a 3,6\% da área total, tendo em vista que havia naquele período apenas um remanescente florestal, o denominado Matão. Atualmente, cerca de $35 \%$ da área total da Terra Indígena Laranjinha vem sendo ocupado por florestas nativas, considerando a somatória de diversos fragmentos (Figura 1).

Espaço Ameríndio, Porto Alegre, v. 8, n. 2, p. 108-126, jul./dez. 2014. 
VITOR RENCK MACIEL e LUIZ ANTONIO NORDER- O processo de restauração florestal...

Figura 1 - Mapa de uso do solo e cobertura florestal da Terra Indígena Laranjinha.

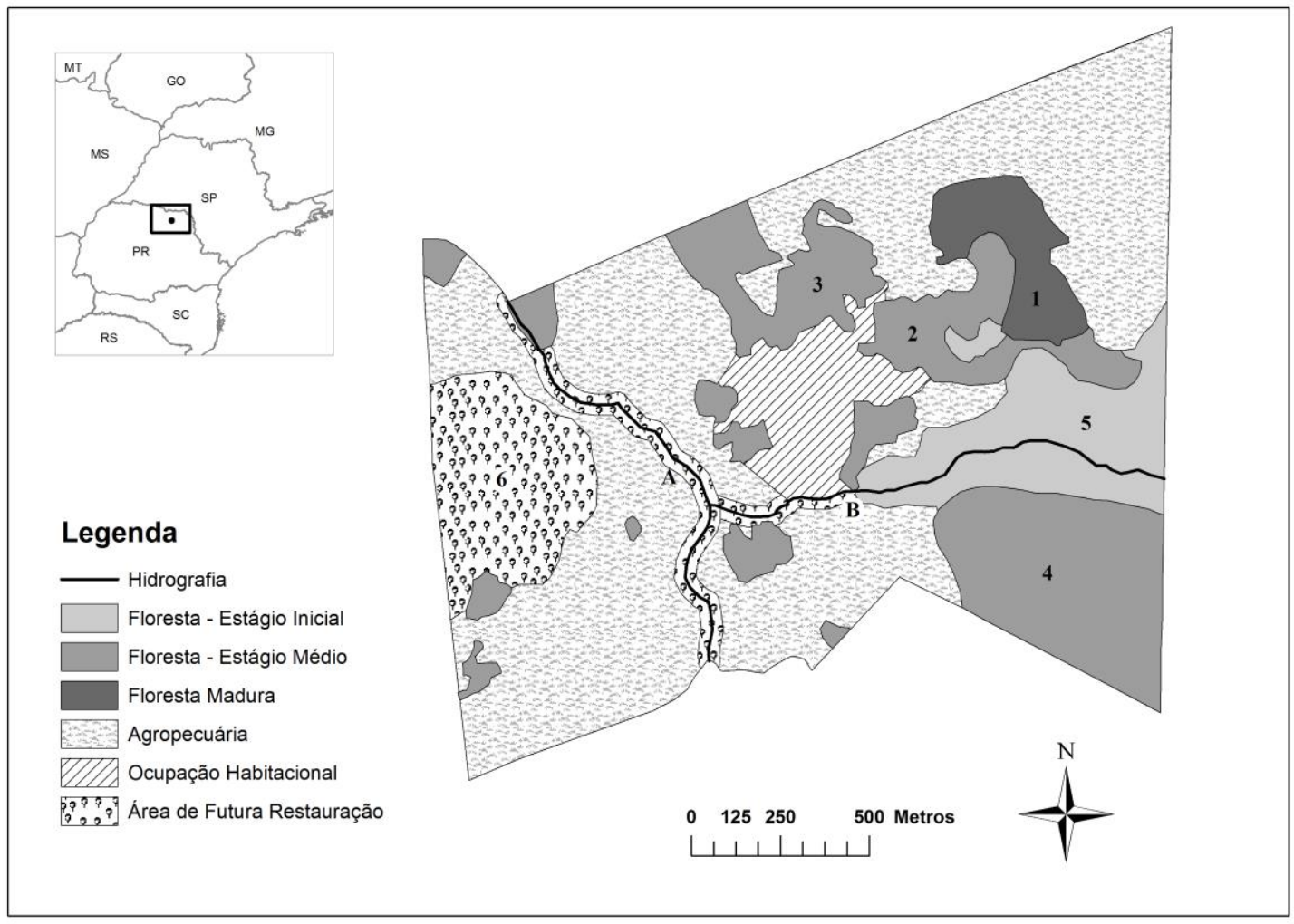

Legenda: Os números representam os principais fragmentos florestais; as letras indicam os dois principais cursos d'água ( $\mathrm{A}=$ Ribeirão Grande; $\mathrm{B}=$ Ribeirão da Onça).

Além do remanescente florestal e sua expansão para o entorno imediato (fragmentos 1 e 2), foram formados, nos últimos quize anos, ao menos dois outros grandes fragmentos (fragmentos 3 e 4) que, somados, alcançam aproximadamente $14 \%$ da área total da aldeia. Os fragmentos 2, 3 e 4 encontram-se, de acordo com os parâmetros estabelecidos pela Resolução CONAMA $n^{\circ} 10$, em um estágio médio de sucessão ecológica, por apresentarem fisionomia arbórea e/ou arbustiva predominando sobre a herbácea; cobertura arbórea variando de aberta a fechada; distribuição diamétrica apresentando amplitude moderada, com predomínio de pequenos diâmetros; serapilheira presente; diversidade biológica significativa e presença de sub-bosque.

Nas diversas áreas em processo de restauração, verificou-se em 2012 uma floresta fisionomicamente densa, com baixa incidência da vegetação de gramíneas. Apesar da diversidade e abundância de espécies vegetais, percebe-se, a predominância de algumas espécies, como mostra o Quadro 2.

Espaço Ameríndio, Porto Alegre, v. 8, n. 2, p. 108-126, jul./dez. 2014. 
VITOR RENCK MACIEL e LUIZ ANTONIO NORDER- O processo de restauração florestal...

Quadro 2 - Espécies arbóreas mais abundantes nas áreas em restauração na Terra Indígena Laranjinha (2012)*

\begin{tabular}{|l|l|l|l|l|}
\hline \multicolumn{1}{|c|}{ Família } & \multicolumn{1}{|c|}{ Espécie } & Nome Popular & $\begin{array}{c}\text { Síndrome } \\
\text { de } \\
\text { Dispersão }\end{array}$ & \multicolumn{1}{c|}{$\begin{array}{c}\text { Grupo } \\
\text { Sucessional }\end{array}$} \\
\hline Euphorbiaceae & Alchornea triplinervia & Tapiá/Jangada & Zoocoria & Pioneira \\
\hline Fabaceae & $\begin{array}{l}\text { Centrolobium } \\
\text { tomentosum }\end{array}$ & Araribá & Anemocoria & Pioneira \\
\hline Fabaceae & Dalbergia frutescens & Imbira & Anemocoria & Pioneira \\
\hline Fabaceae & Parapiptadenia rigida & Gurucaia & Autocoria & Pioneira \\
\hline Fabaceae & $\begin{array}{l}\text { Machaerium } \\
\text { stipitatum }\end{array}$ & Sapuva & Anemocoria & Secundária \\
\hline Lauraceae & Ocotea sp. & Canela & Zoocoria & Secundária \\
\hline Malvaceae & Luehea divaricata & Açoita-cavalo & Anemocoria & Secundária \\
\hline Malvaceae & Guazuma ulmifolia & Mutambo & Zoocoria & Pioneira \\
\hline Moraceae & Maclura tinctoria & Amora-branca & Zoocoria & Pioneira \\
\hline Myrtaceae & Campomanesia sp. & Guabiroba & Zoocoria & Secundária \\
\hline Myrtaceae & Psidium guajava & Goiaba & Zoocoria & Pioneira \\
\hline Verbenaceae & Aloysia virgata & Lixeira & Anemocoria & Pioneira \\
\hline
\end{tabular}

Fonte: Pesquisa de campo, 2011/2012. (*) Classificadas pela síndrome de dispersão e grupo sucessional conforme Carpanezzi e Carpanezzi (2006) e Blum (2008).

Em uma área relativamente extensa, em estágio inicial de sucessão, ao longo do Ribeirão da Onça (fragmento 5), houve, há três anos, com auxílio do IAP, um plantio de 4.800 mudas nativas ao longo desse curso d'água para restauração de sua Área de Preservação Permanente. Havia alguns outros pequenos fragmentos florestais em condições semelhantes, mas que se encontram desconectados e isolados. Do ponto de vista ecológico, a criação de corredores e/ou trampolins ecológicos poderão permitir um maior trânsito da fauna entre os fragmentos e, consequentemente, uma maior eficiência na polinização e dispersão das espécies vegetais.

A intenção das lideranças e demais membros da comunidade era de, em um futuro próximo, fortalecer um contínuo florestal dos fragmentos 1 ao 4 , o que irá perfazer uma cobertura florestal de aproximadamente 90 hectares (31\% da área total). Nos últimos anos, a comunidade definiu que duas outras áreas poderão ser destinadas à restauração florestal: uma delas (Fragmento 6) está situada em uma área de forte inclinação na margem esquerda do Ribeirão Grande, com aproximadamente 23 hectares $-8 \%$ do território; a segunda 
VITOR RENCK MACIEL e LUIZ ANTONIO NORDER- O processo de restauração florestal...

corresponde à Área de Preservação Permanente (APP) deste mesmo curso d'água, além de um trecho da APP do Ribeirão da Onça. A intenção da comunidade é recuperar 30 metros de cada lado dos cursos d'água, conforme a legislação florestal então vigente, englobando uma área de aproximadamente nove hectares.

É muito provável que, nessas áreas, atualmente ocupadas, predominantemente, por capim-colonião e algumas poucas espécies vegetais regenerantes, haja a adoção, nos próximos anos, do mesmo manejo comunitário realizado desde os anos 1990 nos demais fragmentos mencionados acima, com a criação de gado de corte com densidade decrescente associada ao processo de regeneração natural.

A Quadro 3 apresenta as dimensões estimadas para cada forma de uso do solo, de acordo com a pesquisa de campo e a análise de informações georreferenciadas, como mencionado acima. Nota-se que a maior parte das áreas em processo de regeneração encontra-se em estágio médio; há, no entanto, áreas com destinação mais recente à restauração florestal, que apresentam características de um estágio inicial de regeneração.

Quadro 3 - Uso do solo e cobertura florestal na Terra Indígena Laranjinha (2012).

\begin{tabular}{|c|c|c|}
\hline Forma de uso & Área (ha) & Percentual (\%) \\
\hline Floresta em estágio inicial & 25,8 & 8,9 \\
\hline Floresta em estágio médio & 65,5 & 22,5 \\
\hline Floresta madura & 10,6 & 3,6 \\
\hline Área para futura restauração & 32,0 & 11,0 \\
\hline Agropecuária & 140,5 & 48,3 \\
\hline Ocupação habitacional & 16,6 & 5,7 \\
\hline Total & 291 & 100,0 \\
\hline
\end{tabular}

Fonte: Pesquisa de Campo, 2012

Dentre as áreas em restauração florestal, há a predominância de áreas em estágio médio de sucessão, com 65,5 hectares; mas destacase também a incorporação mais recente de algumas áreas a este processo, o que se evidencia com a identificação de 25,8 hectares em situação de estágio inicial de sucessão. Caso venha a se confirmar as intenções da comunidade de expandir a restauração para outras áreas, uma área de $46 \%$ do total passará a ocupada pelas florestas.

Espaço Ameríndio, Porto Alegre, v. 8, n. 2, p. 108-126, jul./dez. 2014. 
VITOR RENCK MACIEL e LUIZ ANTONIO NORDER- O processo de restauração florestal...

\section{Conclusões}

Há poucas décadas, havia na Terra Indígena Laranjinha uma área de apenas 10,6 hectares de cobertura florestal nativa em um total de 291 hectares; a partir da década de 1990, houve um expressivo incremento em termos de área florestada, se levados em conta os estágios inicial e médio da sucessão: um aumento de quase dez vezes em sua cobertura florestal preexistente, passando de 10,6 hectares para 101,9 hectares.

Caso se confirme a restauração florestal de outras duas áreas, como tem sido manifestado pelas lideranças locais, haverá nos próximos anos uma área florestal total de 134 hectares, correspondendo a $46 \%$ da área total. Esses dados evidenciam um grande protagonismo da comunidade em promover a restauração florestal, mesmo em um contexto em que predomina um reduzido acesso à área agricultável.

Entre os principais fatores associados a este processo de restauração florestal estão: a intencionalidade da comunidade em promover a restauração por motivações socioculturais; o estabelecimento de um eficiente manejo visando a restauração florestal a partir de um sistema silvipastoril com densidade decrescente de gado bovino; a política de incentivo financeiro através do ICMS Ecológico; a definição de regras internas restringindo o uso descontrolado do fogo; a perspectiva de um múltiplo uso das florestas a serem restauradas; as limitações topográficas, dada a relativa inclinação de algumas áreas. Destaca-se aqui uma forte simultaneidade entre estes diversos fatores.

A história da restauração florestal entre os Guarani-Nhandewa da Terra Indígena Laranjinha aponta para a importância de uma análise das terras indígenas não apenas para a conservação da biodiversidade, como vem sendo observado, notadamente, na região amazônica, mas também para a restauração de florestas nativas biodiversas em regiões onde predomina um acentuado desmatamento, como é o caso, entre vários outros, do Paraná. 
VITOR RENCK MACIEL e LUIZ ANTONIO NORDER- O processo de restauração florestal...

\section{Referências bibliográficas}

ALMEIDA, Thomaz; MURA. Fábio. Guarani Nãndeva. In: INSTITUTO SOCIOAMBIENTAL. Povos Indígenas no Brasil. São Paulo: ISA, 2003. p. 93-113.

BARROS, Valéria Esteves. Da casa de rezas à Congregação Cristã no Brasil: o pentecostalismo guarani na Terra Indígena Yvyporã Laranjinha/Pr. 2003. $119 \mathrm{f}$. Dissertação (Mestrado em Antropologia Social) - Universidade Federal de Santa Catarina, Florianópolis, [2003].

BERNARD, Harvey Russel. Research methods in cultural anthropology. Newbury Park: SAGE, 1998.

BERNARD, Enrico; FENTON, M. Brock. Bat mobility and roosts in a fragmented landscape in central Amazonia, Brazil. Biotropica, St. Louis, v. 35, n. 2, p. 262-277, 2003.

BERTONCINI, Alzira Politi; RODRIGUES, Ricardo Ribeiro. Forest restoration in an indigenous land considering a forest remnant influence (Avaí, São Paulo State, Brazil). Forest Ecology and Management, Oxford, v. 255, n. 3/4, p. 513-521, 2008.

BLUM, Christopher Thomaz. Lista preliminar de espécies vegetais pioneiras, secundárias e climácicas nativas do Paraná - versão 2008 . Curitiba: Floraparaná/Sociedade Chauá, 2008.

BORGES, Paulo Humberto Porto; BORGES, Liliam Faria Porto. A educação escolar integracionista e a representação fotográfica. Revista Latinoamericana de Tecnología Educativa, Extremadura, v. 8, n. 2, p. 77-90, 2009.

CANCIAN, Nadir Aparecida. A conjuntura econômica da madeira no norte do Paraná. 1974. 217 p. Dissertação (Mestrado em História) - Universidade Federal do Paraná, Curitiba, [1974].

CARPANEZZI, Antonio Aparecido; CARPANEZZI, Odete T. Bertuol. Espécies nativas recomendadas para o Estado do Paraná, em solos não degradados. Colombo: Embrapa Florestas, 2006.

CAVALIN, Mariana; NOGUEIRA, D. C. O movimento dos guarani/mbya à terra sem mal: uma contribuição geográfica. In: XII Encontro de Geógrafos da América Latina. Montevidéu: EGAL, 2009.

CAVIGLIONE, João Henrique et al. Cartas climáticas do Paraná. Londrina: IAPAR, 2000 .

DIEGUES, Antonio Carlos. O mito moderno da natureza intocada. São Paulo: Hucitec, 2008.

Espaço Ameríndio, Porto Alegre, v. 8, n. 2, p. 108-126, jul./dez. 2014. 
VITOR RENCK MACIEL e LUIZ ANTONIO NORDER- O processo de restauração florestal...

INSTITUTO BRASILEIRO DE GEOGRAFIA E ESTATÍSTICA. Manual técnico da vegetação brasileira. Rio de Janeiro: IBGE, 1992.

KAGEYAMA, Paulo Y.; CASTRO, Carlos F. A.; CARPANEZZI, Antonio A. Implantação de matas ciliares: estratégias para auxiliar a sucessão secundária. In: Simpósio sobre Mata Ciliar. Campinas: Fundação Cargill, 1989. p. 130-143.

KÖEPPEN, Wilhelm. Climatologia: con un estudio de los climas de la Tierra. México: Fondo de Cultura Economica, 1948.

MATOS, Wolnei Heleno de; BARROS, O. N. F. Da colonização de Londrina às paisagens florestais atuais: proposição metodológica para estudo de fragmentos. In: YAMAKI, H. et al (Org.). Geografia e meio ambiente: reflexões e proposições. Londrina: Midiograf II, 2006. p. 43-63.

MATTOS, Luciano; HERCOWITZ, Marcelo (Org.). Economia do meio ambiente e serviços ambientais: estudo aplicado à agricultura familiar, às populações tradicionais e aos povos indígenas. Brasília: Embrapa Informação Tecnológica, 2011.

NEPSTAD, D. et al. Inhibition of Amazon Deforestation and Fire by Parks and Indigenous Lands. Conservation Biology, v. 20, n. 1, p. 65-73, 2006.

NIMUENDAJU, Curt Unkel. As lendas da criação e destruição do mundo como fundamentos da religião dos Apapocúva-Guarani. São Paulo: EDUSP, 1987.

NOGUEIRA, Jose Cárlos B.; NOGUEIRA, Luciano Tozzi. Regeneração natural de mata ciliar na Estação Ecológica de Bauru. Revista do Instituto Florestal, Piracicaba, v. 3, n. 2, p. 157-162, 1991.

RODERJAN, Carlos Velozo F. et al. As unidades fitogeográficas do Estado do Paraná. Ciência \& Ambiente, Santa Maria, v. 24, n. 1, p. 75-92, 2002.

THOMAS, D. Wolf et al. The shape of bird - and bat -generated seed shadows around a tropical fruiting tree. Biotropica, St. Louis, v. 20, n. 4, p. 347-348, 1988.

TOLEDO, Victor M. Indigenous peoples and biodiversity. In: LEVIN, Simon (Org.). Encyclopedia of Biodiversity. San Diego: Academic Press, 2003. p. 330-340.

VEIGA, Juracilda. Relatório circunstanciado de identificação e delimitação da Terra Indígena Yvyporã-Yvyporã Laranjinha - PR. Campinas: Funai, 2004.

VELOSO Henrique Pimenta; RANGEL FILHO, Antonio Lourenço; LIMA Jorge Carlos Alves. Classificação da vegetação brasileira, adaptada a um sistema universal. Rio de Janeiro: IBGE (Fundação Instituto Brasileiro de Geografia e Estatística), 1991.

Espaço Ameríndio, Porto Alegre, v. 8, n. 2, p. 108-126, jul./dez. 2014. 
VITOR RENCK MACIEL e LUIZ ANTONIO NORDER- O processo de restauração florestal...

VIEIRA, Eduardo G. M. Relatório de levantamento ambiental: Terra Indígena Yvyporã Laranjinha. Brasília: Funai, 2004.

VIERTLER, Renate B. Métodos antropológicos como ferramenta para estudos em etnobiologia e etnoecologia. In: AMOROZO, Maria Cristina; SILVA, S. P. (Org.). Métodos de coleta e análise de dados em etnobiologia, etnoecologia e disciplinas correlatas. Rio Claro: CNPq/UNESP, 2002. p. 11-30. 